\title{
IMAGINÁRIO DE ESTUDANTES DE GRADUAÇÃO DO CURSO DE FISIOTERAPIA EM RELAÇÃO À DIMENSÃO HUMANÍSTICA DE SUA FORMAÇÃO
}

\author{
Genildes Oliveira Santana Mestre em Desenvolvimento Humano e \\ Responsabilidade Social, Fisioterapeuta do \\ Instituto Federal de Ciência e Tecnologia da \\ Bahia, Docente do Curso de Fisioterapia da \\ Unime Lauro de Freitas. \\ Maribel Oliveira Barreto Pós-doutora em Consciência \\ Transdisciplinaridade e Educação, Pós-doutora \\ em Criatividade e Educação. Doutora em \\ educação Mestre em educação. Especialista em \\ Psicopedagogia. Graduada em Pedagogia.
}

Endereço para correspondência: genildessantana@terra.com.br

Resumo

A dimensão humanística é uma questão relevante na formação do fisioterapeuta. O objetivo desse estudo foi analisar o imaginário de estudantes de graduação do curso de fisioterapia em relação à dimensão humanística de sua formação. Utilizou-se a abordagem qualitativa e a técnica de grupo focal, com sete participantes. Os depoimentos foram gravados e para a sua interpretação foi utilizada a análise do conteúdo. Concluiu-se que existe conscientemente a dimensão humanística na formação desses alunos.

Palavras-chave: Fisioterapia; Autoconhecimento; Educação; Dimensão humanistica.

\section{GRADUATE STUDENTS IMAGINARY OF THE COURSE OF PHYSICAL THERAPY IN RELATION TO THE HUMANISTIC DIMENSION OF THEIR FORMATION}

\begin{abstract}
The humanistic dimension is a relevant aspect during the physical therapists' formation. The purpose of this study was to analyze the imaginary of the physical therapy course undergraduate students in relation to the humanistic dimension of their formation. Qualitative approach and the focal group technique were used, with seven participants. The testimonies were recorded, and the context analysis was used for their interpretation. We conclude that there consciously exist a humanistic dimension in these students' formation.
\end{abstract}

Keywords: Physical Therapy; Self-understading; Education; Humanistic Dimension.

\section{INTRODUÇÃO}

Incontestáveis são os desafios encontrados pelas profissões da área de saúde, neste novo século, em especial a Fisioterapia. Esta jovem profissão, teve seu reconhecimento como atividade de nível superior no Brasil há 44 anos*, em conseqüência do acometimento por Acidente Vascular Encefálico (AVE) do então Presidente Costa e Silva. A despeito de seus poucos anos como profissão de nível superior, a utilização de meios físicos e movimento humano com finalidades terapêuticas remonta há 4000 anos A.C. 
A Fisioterapia é assim definida por Rebelato e Botomé ${ }^{(1)}$ :

A Fisioterapia é uma ciência que utiliza os meios físicos e naturais na promoção da saúde, prevenção de doenças e reabilitação dos indivíduos, com o objetivo de proporcionar uma melhor qualidade de vida, promovendo a sua manutenção ou reintegração das atividades cotidianas.

Concebida inicialmente com abordagem curativa e reabilitadora, passou por importantes alteracões ao longo desses anos de existência. Atualmente, orienta-se em uma concepção que promove a prevenção, promoção e manutenção da saúde, além da reabilitação e reintegração social do indíviduo.

As transformacões na sociedade atual e as demandas contextuais, requerem atualização constante desse profissional. Para tanto, faz-se necessário que os cursos de formação também necessitem de constante atualização para contemplar os avanços e anseios da sociedade.

As propostas formativas indicadas nos projetos pedagógicos das Instituicões de Ensino Superior (IES), seguem as orientacões nas diretrizes curriculares nacionais para o curso. As diretrizes curriculares do curso de Fisioterapia baseadas na Resolução do CNE/CES 04/2002(2) indicam o perfil, as competências e habilidades básicas e especifícas e os temas de estudo para a formação do profissional, pautadas na análise das necessidades e demandas do contexto.

Considerando a dinamicidade do real, novas competências são continuamente incorporadas na atuação profissional. Frente a essas demandas, o profissional deixou de ter suas acões exclusivamente voltadas à reabilitação para atuar como ser humano e está habilitado para atuar em todos os níveis de atenção à saúde, assistindo a comunidade.

Diante do exposto não podemos negar a relevância da adequada preparação integral do futuro fisioterapeuta, priorizando o autoconhecimento e o despertar da Consciência destes acadêmicos, para que consigam visualizar os pacientes como Seres Humanos em sua totalidade. Nesta perspectiva, é preciso que este profissional reconheça sua complexidade e sua história singular nos diferentes estágios de vida e a necessidade que têm de ajuda, compreensão e orientação profissional.

Teixeira $^{(3)}$ afirma que este profissional deverá ser possuidor de pensamento crítico, atitudes questionadoras, ter habilidades para enfrentar situacões mutantes

\footnotetext{
* Decreto-lei 983/69, assinado no dia 13 de outubro de 1969, pela junta militar que governava o país.
} 
(criatividade), ser cordial, solidário, tolerante, paciente, perseverante, além de ser íntegro, honesto e respeitoso às leis naturais, preservando o meio ambiente. A formação humanística, ética e emancipadora, voltada à reflexão, à construção do conhecimento e à integralidade, poderá direcionar o futuro profissional aos padrões atualmente desejados pela sociedade.

Em consonância com o perfil almejado para o fisioterapeuta, o relatório UNESCO (DELORS), ${ }^{(4)}$ relativo à educação para o século XXI, confirma que a finalidade da educação é contribuir efetivamente para o desenvolvimento total da pessoa — espírito e corpo, inteligência, sensibilidade, sentido estético, responsabilidade pessoal e espiritualidade.

Neste sentido, acreditamos que o papel da educação vai muito além da transmissão do conhecimento acumulado de uma geração para outra, indo ao encontro da necessidade de conscientização, contribuindo para que o educando conquiste sua identidade com base na construção de uma visão integrada de si mesmo.

Consciente do papel da educação e de sua prática ainda pautada no paradigma cartesiano-newtoniano — marcado pela fragmentação da aprendizagem e do ser humano e também pelo desenvolvimento lógico-racional, cuja visão compartimentalizada da realidade impede que as potencialidades humanas se desenvolvam, produzindo conhecedores de assuntos técnicos, porém inábeis e imaturos ao lidar com questões afetivas, psicológicas e emocionais — precisamos refletir acerca da necessidade de mudancas na forma de educar o fisioterapeuta do novo milênio.

Conceituamos imaginário, com base nas contribuições de Maffesoli ${ }^{(5)}$, pensador francês que assim o define:

O imaginário é algo que ultrapassa o indivíduo, que impregna o coletivo ou, ao menos, parte do coletivo. É o estado de espírito de um grupo, de um país, de um Estado-Nação, de uma comunidade, estabelece vínculo. Logo, se o imaginário liga, une numa atmosfera, não pode ser individual. Pode-se dizer que imaginário é a cultura de um grupo, é uma sensibilidade, não uma instituição [...] $\mathrm{O}$ imaginário é determinado pela idéia de fazer parte de algo. Partilha-se uma filosofia de vida, uma linguagem, uma atmosfera, uma idéia de mundo, uma visão das coisas, na encruzilhada do racional e do não-racional.

Diante do exposto, o objetivo desse estudo foi analisar o imaginário de estudantes de graduação do curso de fisioterapia, em relação à dimensão humanística de sua formação. 


\section{METODOLOGIA}

Estudo de natureza exploratório-descritivo com abordagem qualitativa na análise das informações. A estratégia de pesquisa considerada foi o estudo de caso. Utilizamos como técnicas para busca de informações, o grupo focal e a entrevista.

De um total de 64 formandos do curso de fisioterapia de uma EIS X, contamos com a participação de 7 alunas, consideradas como universo de investigação, dentre os 12 alunos convidados para participarem da pesquisa, no grupo focal. Todas as participantes eram formandas da primeira turma do curso de fisioterapia da IES onde ocorreu a pesquisa, sendo o critério de inclusão para a presente pesquisa. A faixa etária das participantes variou de 22 a 43 anos. Em relação ao estado civil, encontramos uma casada e as demais solteiras. Procuramos identificar estudantes com disponibilidade de tempo, com faixa etária variável e estado civil diferenciado, para conhecermos as diversas opiniões e contribuições aos objetivos da pesquisa. Foi realizado um encontro com estudantes de graduação do curso de fisioterapia, para a realização do grupo focal e coleta das informações necessárias à pesquisa. $\mathrm{O}$ encontro para a realização do grupo focal aconteceu no dia 14 de junho de 2007, na Clínica Escola de Fisioterapia da IES X, localizada, na região metropolitana de Salvador. A duração do grupo focal foi de aproximadamente duas horas e meia. Após os esclarecimentos sobre os objetivos do estudo, foi solicitada a cada uma das participantes a assinatura do Termo de Consentimento Livre e Esclarecido. Em seguida, lemos as questões norteadoras, que favoreceram a discussão, servindo de roteiro para nossa moderação, facilitando a condução do trabalho grupal ao encontro dos objetivos da pesquisa.

Para realizarmos a coleta de informações junto às discentes formandas, lançamos mão da técnica de entrevista estruturada, realizada durante o grupo focal. Elaboramos quatro questões que enfatizaram aspectos relacionados às competências e habilidades técnicas e humanísticas da formação do fisioterapeuta e o processo de autoconhecimento, visto que nosso objetivo estava pautado no imaginário destas alunas em relação a essas vertentes de sua formação.

Após o término do trabalho em grupo, organizamos o material coletado e sistematizamos o processo de análise. Assim posto, realizamos a transcrição dos depoimentos, que foi o momento oportuno para resgatarmos o encontro estabelecido, na

Revista Pesquisa em Fisioterapia. 2013 Dez;3(2): 168-181 
busca da compreensão do que estava entre as afirmações colocadas e os gestos das estudantes diante das questões formuladas.

As categorias de analise foram definidas como: competências e habilidades necessárias a formação do fisioterapeuta; se foram contempladas na formação essas competências e habilidades; autoconhecimento, e sua relação com a pratica profissional.

Mantivemos o anonimato das participantes, substituindo seus nomes por números de 1 a 7.

\section{RESULTADOS E DISCUSSÃO}

\section{fisioterapeuta. \\ Categoria 1: competências e habilidades necessárias a formação do}

As falas das participantes da pesquisa corroboram o entendimento de Teixeira ${ }^{(3)}$ que complementa com a necessidade deste profissional ser cordial, solidário, tolerante, íntegro, paciente e perseverante.A empatia também citada por Vieira ${ }^{(6)}$ como uma das mais relevantes ferramentas para a relação terapeuta/paciente e facilitador/estudante.

Chamou nossa atenção o depoimento no qual a estudante comentou sobre a competência para a relação inter e multidisciplinar na atuação do fisioterapeuta, corroborando o entendimento de Gava. ${ }^{(7)}$ Consoante este autor há melhora na qualidade do atendimento, quando as atividades integradas entre as disciplinas do curso de fisioterapia e outros cursos são desenvolvidas, tornando estes profissionais mais humanizados.

O cuidado foi bastante evidenciado nas falas das entrevistadas, como um dos fatores fundamentais para o sucesso do tratamento fisioterapêutico. Neste sentido a compreensão das alunas se coaduna com o pensamento de $\mathrm{Volich}^{(8)}$ que diz: "O cuidado pressupõe um exercício permanente de liberdade, que permita ao cuidador entrar em contato com as sensações, fantasias e emoções do outro e também com aquelas pessoas mobilizadas em si pelo paciente". Entendemos a relação terapeuta/paciente como um aprendizado contínuo, tal como exposto por Gimenes ${ }^{(9)}$ : "Cuidar é servir, é oferecer ao outro em forma de serviço, o resultado de nossos talentos, preparo e escolhas." Silva ${ }^{(10)}$ reitera: “[...] é um sentimento/ação que requer atenção, é um estar presente."

A importância do contato e do toque recebeu destaque nas observações realizadas pelas estudantes, confirmando o que diz Braz, ${ }^{(11)}$ quando afirma que o toque 
possui poder profundamente terapêutico sobre corpo, mente e espírito, transmitindo amor consciente ou não. Para esse autor o contato físico induz a um estado emocional positivo que ajuda o ser em seu processo de cura.

Conforme comentário das entrevistadas, ficou demonstrada a necessidade que Leloup ${ }^{(12)}$ advoga; para se tornar um profissional completo, é necessária a união do técnico com o humano, para que o resultado apareça nas ações com o paciente.

O fisioterapeuta tem que ser técnico sim, mas ele deve ser muito mais humanista antes de qualquer coisa. Isso porque a Fisioterapia exige contato. Você tem que ter muita proximidade com o outro. Nós temos que nos desprover de tudo. Tivemos essa experiência agora no hospital. Se você não perceber o outro (paciente), você não conseguirá interagir com ele; você não terá resultados e nós tivemos muitos resultados claros lá no Hospital, onde realizamos o estágio. Todo e qualquer contato deve ser feito de uma maneira mais humana. Aluna 6 Acho que o profissional precisa dominar a técnica. Mas acredito que devemos tratar o paciente como se o mesmo fosse uma pessoa bem próxima da gente, um parente querido; com toda competência, mas também com carinho, palavras de incentivo, de conforto... Muitas vezes, na Fisioterapia, não há precisão de se tocar no paciente, não há necessidade de se fazer um exercício. Não é raro encontrarmos pacientes com problemas psicológicos, com problemas emocionais. É preciso ter muita sensibilidade para lidar com situações desse tipo. Aluna 5.

O saber ouvir é, para mim, a coisa mais importante para um fisioterapeuta. Pelo menos foi isso que aprendi durante esses cinco anos. Aluna 4.

Antes de realizar qualquer atendimento, procuro conhecer o paciente; procuro conhecê-lo, criar uma aproximação, animá-lo de alguma maneira. Nem sempre a pessoa se encontra disposta, psicologicamente preparada para realizar algo. É preciso que tenhamos uma participação efetiva do paciente, para que possamos atingir um ganho através do processo de reabilitação. A parte psicológica, física e emocional está diretamente interligada. Por isso, procuro criar um vínculo com o meu paciente, antes de qualquer coisa, para só depois iniciar um tratamento. Tudo isso é necessário se quisermos obter resultados positivos com o Ser Humano. Aluna 3.

Acho que uma pessoa, para ser um fisioterapeuta, precisa estar a par do paciente como uma maneira de conhecê-lo melhor. Muitas vezes, o que está escrito nos prontuários não traduz a verdade do paciente. Devemos conversar, ouvir, saber, tentar entender e ajudar da melhor maneira possível o paciente $e$ realizar tudo aquilo que for necessário para a sua reabilitação.... São pessoas que vieram para somar na sua vida. Pessoas que vieram na sua vida e não foram embora... [mais choro]. Aluna 7.

Eu digo de você conversar, ter uma boa relação com as pessoas da equipe multidisciplinar. Ter um bom relacionamento na área hospitalar com todos os profissionais, porque isso servirá como um estímulo para você no decurso do tratamento. Aluna 1. 


\section{Categoria 2: Contribuição da IES para o desenvolvimento das competências e habilidades do graduando em Fisioterapia}

Em relação à segunda categoria, as estudantes afirmaram ter aprendido muito para o desenvolvimento dessas competências e habilidades durante o curso de fisioterapia da IES X, não somente na sala de aula, mas também na prática do dia-a-dia, inclusive entre os próprios colegas. Esta constatação nos remete ao relatório da Unesco $(\text { DELORS })^{(4)}$ que contempla em um de seus pilares, o aprender a viver juntos, onde aprendemos a viver em sociedade, respeitando a diversidade do ser, praticando a inclusão e nos preparando para as inter-relações. Esta compreensão alcançada pelas alunas que participaram do grupo focal, de uma questão tão necessária à formação desse profissional, leva-nos a supor que estas futuras profissionais conseguiram desenvolver em seu período de formação na IES X a humanização e o comprometimento com seu papel de fisioterapeutas na sociedade.

Algumas estudantes referem, inclusive, dificuldades na vida pessoal, que foram evoluindo com o auxílio de lições aprendidas no decorrer do curso, melhorando aspectos globais em sua vida pessoal no convívio com colegas, professores e pacientes. Neste sentido, reafirmam o que diz Buber, ${ }^{(13)}$ quando fala que precisamos ir ao encontro do outro para que possamos nos conhecer.

Esta questão é também abordada por Souza ${ }^{(14)}$ ao afirmar que o processo de transformações internas da pessoa, por conta das experiências educacionais, ocorre a cada dia de um curso, fazendo com que o aluno adquira novos conhecimentos, novos valores e postura profissional. Ressaltamos ainda o papel da universidade nesse contexto evolutivo do ser humano para alcançar maior maturidade e abertura de espírito, de acordo com o entendimento de Boff. . $^{(15)}$

Foi comentada a relevância dos estágios no aprendizado das fisioterapeutas. As participantes da pesquisa reconheceram que este é o momento em que a teoria é aliada à pratica, promovendo o desenvolvimento de competências e habilidades necessárias a sua formação. Entretanto também discutiram o momento em que ele ocorre no curso, reconhecendo que poderia iniciar mais cedo. Segundo Valsecchi, ${ }^{(16)}$ nas diversas partes do país, os estágios ocorrem tardiamente nos cursos, o que poderá gerar profissionais menos habilitados para o mercado de trabalho, pois, na formação curricular, ocorre apenas no último ano de formação, podendo ocorrer uma dissociação entre teoria e 
prática, gerando consequências no desempenho dos futuros profissionais. $\mathrm{O}$ autor entende que se deve proporcionar maior participação do aluno em situações de vida real

Constatamos que os professores que possuíam mais competências humanísticas, eram os mais amados pelas estudantes. Consoante Moreira, ${ }^{(17)}$ a prática da teoria humanística ocorre com a identificação e relação, por meio da interação entre as pessoas, trazendo uma excelente contribuição para o processo educativo e para a vida do ser humano. Paulo Freire ${ }^{(18)}$ reconhece que este tipo de educação estimula a criatividade humana, tem do saber uma visão crítica, tal como percebido em algumas falas das alunas.

Para Ornstein e Hunkins, ${ }^{(19)}$ o foco de tal abordagem não está nas conquistas acadêmicas, mas no indivíduo em sua totalidade, em suas necessidades sociais, psicológicas, físicas. O papel do professor e do currículo é, portanto, enxergar o aluno como uma pessoa completa. Acreditamos que estes professores transmitiram algumas idéias da teoria humanística em suas práticas educativas.

Foram comentadas experiências com pacientes, que muito marcaram a vida das entrevistadas em seu período de formação e fizeram-nas refletir acerca dos casos apresentados, muito além da reabilitação. Acreditamos que essas futuras profissionais, que tiveram uma formação mais humanizada, visualizaram os pacientes como seres humanos, em sua totalidade, com sua complexidade, em diferentes estágios de vida e com histórias singulares, mas necessitando de ajuda, compreensão e orientação profissional adequada a seu momento de vida, conforme comenta Davis ${ }^{(20)}$.

Vejamos as falas das estudantes:

Sim. Durante esses cinco anos aqui dentro, vimos isso não só em sala de aula. A partir desse instante, a aluna continua o seu depoimento entre lágrimas $e$ soluços. Um depoimento carregado de emoção - Vocês me receberam de braços abertos e em nenhum momento vocês me discriminaram, apesar da grande diferença de idade. A nossa experiência na clínica foi muito grande. Foi aqui que realizei a minha primeira experiência de estágio. [...] Acho que aqui foi uma escola onde aplicamos todo conhecimento teórico, na prática, de maneira grandiosa. Eu tive diversos exemplos aqui, mas sou suspeita em falar, porque eu amo a [...] [mais choro], eu amo a minha escola, não estou conseguindo elaborar minha mensagem, porque fico pensando como é que vai ser depois..... Tive esse testemunho aqui, convivendo com vocês. Aluna 6.

Procuro analisar cada caso: pacientes resistentes ao tratamento, deprimidos, com baixa estima, outros menos resistentes. mas podemos nos melhorar a todo instante [...] Me ajudou muito [o curso desta IES]! A base veio de História e Fundamentos, e foi se ampliando com as outras disciplinas. Comecei a amar a Fisioterapia em História e Fundamentos... [risos ao fundo - das outras alunas, pelo fato da colega ainda não ter conseguido parar de chorar], onde se mostra 
o que é a Fisioterapia, o que fazemos, e até aonde podemos ir. Foi quando me descobri. Depois vieram outros professores que nos orientaram a atender bem o paciente, a dar carinho... O paciente está em primeiro lugar.... Eu tinha isso; eu tenho isso. Isso é da minha natureza, mas a minha faculdade contribuiu, e muito, para o meu aprimoramento. Aluna 3.

[...] está de parabéns por nos proporcionar o desenvolvimento desse lado humanístico com os pacientes desde o princípio. Podemos observar que, no decorrer do curso, os professores que mais idolatramos, mais adoramos, são aqueles que possuem o lado humanista mais desenvolvido.. Se entrássemos em contato mais cedo com o paciente no curso de Fisioterapia, sairíamos para o mercado com uma competência fantástica. Aluna 5.

Acho que o curso de Fisioterapia contribuiu para a minha formação. Eu aprendi a tocar, o curso faz com que você aprenda a tocar e eu cresci muito, também, vendo outros professores que tinham esse lado; que olhavam para o aluno e detectavam as suas dificuldades e que procuravam nos auxiliar da melhor maneira possível. Com certeza aprendi muito aqui. Aluna 4.

A faculdade contribuiu de tal forma, que hoje tenho um olhar crítico que me possibilita perceber, ao chegar a uma instituição, a falta de humanização vindo do terapeuta, do nosso colega que estudou como a gente, que deveria ter tido a base que a gente teve... Sinto falta disso quando chego em determinadas clínicas, em determinados locais de atendimento. Aluna 3.

Acho que a proposta da instituição está dentro daquilo que ela se propõe. Mas quanto à questão humanista. Quanto a isso ela nos preparou. A gente teve isso não só aqui, mas lá na sala de aula com os exemplos. Nós temos muitos exemplos. Aluna 5.

No curso de Fisioterapia não se aprende só a técnica, mas muito mais o humanismo. [Choro - a aluna continua respondendo emocionada] Os estágios, realizados aqui na clínica e no hospital, me ensinaram bastante.. Para mim foi muito bom, essencial, pois me ajudou a trabalhar minha timidez, a lidar melhor com ela. Ter o prazer em atender, de receber um presente do paciente. Uma demonstração de gratidão por tudo o que você fez. Só tenho que ficar feliz. Aluna 2.

\section{Categoria 3: Definição de autoconhecimento}

Várias foram às definições de autoconhecimento fornecidas pelas entrevistadas, fruto de suas crenças e vivências, apontando para diferenças significativas nas concepções formuladas. Extraímos algumas palavras das definições, conforme citaremos a seguir: conhecer a si próprio, saber, reconhecer os seus defeitos e também as suas virtudes; saber administrar, saber lidar com o outro, ter autocrítica, autocontrole, saber antecipadamente suas reações frente as diversidades, autoconhecimento anda em paralelo com crescimento individual, prática, percepção, mudança, transformação, é crescente, quando percebemos nossos defeitos, aceitamos melhor o outro.

Revista Pesquisa em Fisioterapia. 2013 Dez;3(2): 168-181 
Pudemos constatar que as definições produzidas pelas entrevistadas ressoam nas idéias dos teóricos, que demonstram a urgente necessidade do desenvolvimento do autoconhecimento para a humanidade. Buber, ${ }^{(13)}$ por exemplo, diz que só é possível o encontro do ser humano consigo mesmo, quando do encontro do indivíduo com o outro. Para Khrishnamurti, ${ }^{(21)}$ o autoconhecimento é essencial para nos transformarmos e, por conseguinte, é o começo para a transformação ou regeneração da humanidade. Para Maslow, ${ }^{(22)}$ urge buscar-se o autoconhecimento, que é o começo da sabedoria e, por conseguinte, o começo da transformação ou regeneração. Consequentemente, a transformação do mundo se efetiva pela modificação do indivíduo, porque ele é o produto total da existência humana; mas, para isso, é preciso o desejo de mudanças.

Sobre o autoconhecimento, as alunas declararam:

É você se conhecer, saber, reconhecer os seus defeitos e também as suas virtudes; saber administrar, saber lidar com o outro, pois a partir do momento que você percebe seus defeitos, você talvez até entenda melhor o outro. [...]. Eu costumo fazer muita autocrítica e conceituo autoconhecimento como isso: você se conhecer, se perceber, perceber o outro e aceitá-lo como ele é, e isso não é fácil. É preciso estar sempre exercitando isso, até dentro de casa com o filho, o marido... Ter sempre em mente que as pessoas são diferentes. Aluna 6.

Autoconhecimento para mim é você saber quem você é, do que você é capaz, das suas limitações e saber que nada disso é estático. Você está sempre mudando. Procurar se melhorar sempre. Aluna 1.

Acho que é você saber suas qualidades e limitações e poder trabalhar em cima disso, tentando melhorar, isso não implica em uma modificação do caráter, porque isso não se modifica. $O$ autoconhecimento é algo que acontece todos os dias. Cada dia vou me conhecendo muito mais e ainda tenho muito que me conhecer. Aluna 2.

\section{Categoria 4: Relação de autoconhecimento e atuação profissional.}

E, finalmente, quanto ao tema da última pergunta relativo ao processo de autoconhecimento e atuação profissional, as estudantes tiveram opiniões parecidas no que tange à importância desta integração entre técnica e humanização para uma reabilitação eficaz da população.

De acordo com o relatório da Unesco, ${ }^{(4)}$ o pilar aprender a ser traduz-se na relação do educando consigo mesmo, na busca pelo autoconhecimento, base para que sejam contemplados $o$ aprender a fazer, a conhecer e a viver juntos alicerce para o desenvolvimento humano e para a responsabilidade social de suas ações pessoais e profissionais. 
Observamos a imensa responsabilidade da educação para a formação do ser humano profissional, que se bem conduzido e estimulado em suas descobertas, tendo oportunidade de ir ao encontro de si próprio e do outro, certamente, tornar-se-á um profissional em sua totalidade, contribuindo para a paz e a harmonia do universo, como defendem Barreto, ${ }^{(23)}$ Krhisnamurti $^{(20)}$ e Soares, ${ }^{(24)}$ entre outros.

Como argumentam Rogers e Rosemberg ${ }^{(25)}$ : "É necessário a colocação do homem inteiro em todos os seus comportamentos e em tudo que por ele é criado." Portanto o fisioterapeuta deve considerar o autoconhecimento como peça fundamental de sua formação profissional.

Ficou evidenciada a concordância entre as entrevistadas sobre a relevância do conhecimento de si mesma como ferramenta indispensável em sua prática profissional. Acreditamos que as ações direcionadas a assistência fisioterapêutica serão mais humanizadas, podendo guiar estes profissionais para as necessidades e anseios da sociedade.

Você saberá como cuidar melhor do outro, a partir do momento em que você se autoconhece. Você sabe dos seus limites, de suas necessidades... Então como a Fisioterapia é doação, $n$ toque doar ao máximo [...]. Aluna 4.

Acho importante o profissional de Fisioterapia ter esse autoconhecimento. Isso colaborará muito na hora de entender, de tratar o paciente, que muitas vezes tem uma forma de agir e pensar diferente da sua. O autoconhecimento está muito relacionado com a profissão [...] Aluna 5.

Acho que com o autoconhecimento nos perguntamos o que seria o ideal de um bom profissional, e procuramos trabalhar em nós aquilo que achamos importante, que deve ser inerente a esse profissional. Ver nossas limitações quanto a isso e trabalharmos o que identificarmos como mais difícil, como no caso da timidez. Trabalhar isso para melhor chegar ao paciente, e observar o lado oposto: se o paciente for tímido, tenho que ter um tipo de abordagem diferente de um outro extrovertido. Aluna 6.

O autoconhecimento está muito relacionado com a profissão. Aluna 7.

\section{CONSIDERAÇÕES FINAIS}

Ao analisarmos o imaginário de estudantes de graduação do curso de fisioterapia em relação à dimensão humanística de sua formação, constatamos que dentre as competências e habilidades mais citadas durante a pesquisa, destacaram-se aquelas que priorizam as inter-relações, tais como respeito, atenção, dedicação, amor ao que faz e paciência, perpassando por uma atitude mais crítica e reflexiva em suas ações. Esta constatação reforça a presença da abordagem humanística em sua formação, 
corroborando o que as Diretrizes Curriculares Nacionais dispõem para o curso de Fisioterapia.

Ficou evidenciada a relevância atribuída pelas alunas à dimensão humanística de sua formação, em detrimento das técnicas, quando relataram a contribuição significativa em suas vidas pessoal e profissional ao final da realização do curso de graduação. Para nós ficou nítida a responsabilidade da educação como importante instrumento de transformação do ser humano, permitindo-lhe alçar o autoconhecimento, o conhecimento do outro, a leitura crítica de uma realidade na qual está inserido.

Para o desenvolvimento do ser humano em sua totalidade, é necessário, inicialmente, que se trabalhe o processo do autoconhecimento. Para que este ocorra, devemos ter a vontade como aliada, buscar a autopercepção e o centrar-se em si mesmo. Ao equilibrar o modo como age, pensa e sente, o ser humano poderá criar relações mais harmônicas em seu dia-a-dia, quer em sua vida pessoal, quer profissional. O autoconhecimento é facilitado, quando, na formação do estudante de graduação de fisioterapia, a abordagem humanística é praticada.

Portanto urge que busquemos promover uma educação mais humanizada e integral do ser, buscando a subjetividade do ser humano, aceitando suas diferenças socioculturais, seus diferentes estilos cognitivos. O processo identitário do ser humano não é construído de modo isolado, mas no conjunto, na troca, nas relações, embora se expresse na singularidade de cada um.

Quanto ao autoconhecimento e sua relação com a profissão, as entrevistadas foram unânimes ao confirmarem a relevância desta vertente para a prática profissional do fisioterapeuta que, ao conhecer-se, pode tratar, conviver, entender, aceitar e compreender o outro em sua totalidade.

Estamos cientes dos limites das conclusões permitidas por esta pesquisa, mas pudemos entender que os fenômenos por ela investigados estão presentes em um universo muito mais amplo que o estudado e, por isto, é imprescindível que as pesquisas tenham continuidade, para permitir o aprofundamento do conhecimento das questões que envolvem a formação de Fisioterapia.

\section{REFERÊNCIAS}

1. Rebelatto JR, Botomé SP. Fisioterapia no Brasil. Fundamentos para uma ação preventiva e perspectivas profissionais. $2^{\mathrm{a}}$ ed. São Paulo: Manole; 1999. 
2. CNE - Conselho Nacional de Educação. Resolução CNE/CES 4/2002. Institui Diretrizes Curriculares Nacionais do Curso de Graduação em Fisioterapia. Diário Oficial da União, Brasília, 4 de março de 2002. Seção 1, p. 11.

3. Teixeira CF. O futuro da prevenção. Salvador: Casa da Qualidade; 2001. 4. Delors J et. al. Educação: um tesouro a descobrir. Relatório para a UNESCO da Comissão Internacional sobre a Educação para o século XXI. 10ª ed. São Paulo: Cortez; Brasília, DF: MEC/UNESCO; 1999.

5. Mafessoli M. Mafessoli: Entrevista. Entrevistador: Juremir Machado de Silva. Revista Famecos. 2001;15:74-81.

6. Vieira G. A construção das bases para o desenvolvimento de um software CBT tendo como conteúdo central um teste de avaliação da inteligência emocional [dissertação]. Florianópolis: Faculdade de Engenharia da Universidade Federal de Florianópolis; 2003. [acesso em 2007 maio 25] Disponível em: http://teses.eps.ufsc.br/Resumo.asp?5184

7. Gava MV. Fisioterapia: história, reflexões e perspectivas. São Bernardo do Campo: UMESP; 2004.

8. Volich RM. O cuidar e o sonhar. O mundo da saúde. 2000;24(4):235-236.

9. Gimenes OM, Silva MJ. Eu-cuidador. O mundo da saúde. 2000;24(4):207-309.

10. Silva MAPD. O cuidar do paciente terminal: questões éticas. O mundo da saúde. 2000;24(4):272-277.

11. Braz MM. Educação integral: um modelo de ensino da fisioterapia baseada na física quântica [tese]. Florianópolis: Faculdade de Engenharia da Universidade Federal de Santa Catarina; 2006.

12. Leloup JY. Caminhos da realização. Rio de Janeiro: Vozes; 1997.

13. Buber M. Eu e tu. $10^{a}$ ed. São Paulo: Centauro; 2006.

14. Souza RMAN. de. A formação do aluno e sua atuação na Disciplina Prática Clínica Supervisionada no curso de Fisioterapia - FURB [dissertação]. Blumenau:

Universidade Regional de Blumenau; 2004.

15. Boff L. Ética da vida. Brasília: Letra Viva; 2000.

16.Valsecchi EASS, Nogueira MS. Fundamentos de enfermagem: incidentes críticos relacionados a prestação de assistência em estágio supervisionado. Rev. Latino-Am. Enfermagem. 2002;10(6):819-24.

17. Moreira MA. Teorias de aprendizagem. São Paulo: Editora Pedagógica e Universitária; 1999. 
18. Freire P. Resumo de palestras. Sob o patrocínio da OEA, do Governo do Chile e da Universidade do Chile. Santiago; 1967.

19. Ornstein A, Hunkins FP. Curriculum: foundation, principles and theory. $2^{\mathrm{a}}$ ed. Needham Heights: Allynaud Bacon; 1993.

20. Davis CM. Influência dos valores na assistência ao paciente: fundamentos para tomada de decisões. In: O'Sullivan Susan B.; Schmitz Thomas J. Fisioterapia avaliação e tratamento. $4^{\mathrm{a}}$ ed. São Paulo: Manole, 2004. p. 135-147.

21. Krishnamurti J. A educação e o significado da vida. São Paulo: Cultrix; 1985.

22. Maslow HA. El hombre autorealizado. 10ª ed. Barcelona: Kairós; 1993.

23. Barreto M. Consciência e educação. In: Simpósio Nacional Sobre Consciência; 2006; Salvador: Fundação Ocidemnte. 1 CD-ROM.

24. Soares NS. A consciência da arte de aprender para o autodesenvolvimento do ser humano. In: Simpósio Nacional Sobre Consciência; 2006; Salvador: Fundação Ocidente. 1 CD-ROM.

25. Rogers C, Rosemberg RL. A pessoa como centro. São Paulo: Asp; 1977. 